Original Article

\title{
Comparison of Spatiotemporal Gait Parameters between Children with Normal Development and Children with Diplegic Cerebral Palsy
}

\author{
Chang Ju Kim, MS, $\mathrm{PT}^{1)}$, Sung Min Son, PhD, $\mathrm{PT}^{2)^{*}}$ \\ 1) Department of Physical Therapy, College of Rehabilitation Science, Daegu University \\ 2) Department of Physical Therapy, College of Health Science, Cheongju University: 298 Daeseong-ro, \\ Cheongju-si, Chungbuk 363-764, Republic of Korea
}

\begin{abstract}
Purpose] The purpose of this study was to determine the differences in spatiotemporal gait parameters between children with spastic diplegic $\mathrm{CP}$ and children with normal development (ND). [Subjects and Methods] Sixteen children (eight children with spastic diplegic CP and eight ND children) were recruited for participation as volunteers in this study. The children with CP had a Gross Motor Function Classification (GMFC) System level of between I and II. [Results] Walking velocity, cadence, stride length, and step width of children with CP with a GMFC of between I and II were a level of $60 \%, 77 \%, 73 \%$, and $160 \%$, respectively, of those of ND children. The percentages of right and left double-limb support were $188 \%$ and $179 \%$ higher, respectively, and the proportion of single limb support was shorter by $83 \%$ and $82 \%$. [Conclusion] Our results provide objective evidence of distinct differences in spatiotemporal gait parameters between children with spastic diplegic CP with a GMFC level I or II and ND children and would be helpful to persons involved in the care of these children.

Key words: Cerebral palsy, Spatiotemporal gait parameter, Gait pattern
\end{abstract}

(This article was submitted Jan. 7, 2014, and was accepted Feb. 20, 2014)

\section{INTRODUCTION}

Children with cerebral palsy (CP) have a neurodevelopmental disorder due to a nonprogressive lesion of the immature brain occurring early in infancy or during the fetal term $^{1,2)}$. Motor disorders of children with $\mathrm{CP}$ are related to primary deficits (such as spasticity, muscle weakness, reduced coordination, and a loss of selective motor control) and secondary deficits (such as muscle contracture and bone deformities $)^{3,4)}$. These changes can affect voluntary muscle recruitment and lead to impairment of motor ability. Compared with children with normal development (ND), children with $\mathrm{CP}$ have various muscle recruitment patterns and magnitudes ${ }^{5}$.

Abnormal gait is a common problem in children with $\mathrm{CP}$. Because of motor weakness and poor voluntary motor control, crouched gait or diplegic gait is an important functional biomarker in children with spastic diplegic $\mathrm{CP}^{6,7)}$. In addition, gait in children with $\mathrm{CP}$ is characterized by a slower walking speed, a shorter-stride length, and more time spent in double support ${ }^{8)}$. Due to the abovementioned problems, a general decrease in physical activity as well as walking capacity has been observed in children with CP.

*Corresponding author. Sung Min Son (E-mail: ssm0417@ hanmail.net)

(C2014 The Society of Physical Therapy Science. Published by IPEC Inc. This is an open-access article distributed under the terms of the Creative Commons Attribution Non-Commercial No Derivatives (by-ncnd) License $<$ http://creativecommons.org/licenses/by-nc-nd/3.0/> .
Van den Berg-Emons et al..$^{9)}$ and Bjornson et al. ${ }^{10)}$ reported that school-age children with diplegic $\mathrm{CP}$ were less physically active than ND children. Decreased physical activity in children with CP may be related to gait capacity. These characteristic features influence quality of life of children with $\mathrm{CP}$ by reduction of daily life activities and independent mobility ${ }^{11)}$. Although it is well recognized that children with CP have poor gait capacity and physical activities, the majority of the scientific literature in children with $\mathrm{CP}$ has focused on kinetics and kinematics in assessment of gait analysis. In addition, previous studies have not included a direct comparison of school-age children with $\mathrm{CP}$ and agematched ND children.

Gait capacity limitations in children with $\mathrm{CP}$ appear to be related to the ability to participate in day school activities, such as playground games and moving to other areas of the school ${ }^{12)}$. Increasing the knowledge concerning the difference in gait capacity between children with spastic diplegic CP and age-matched ND children can be helpful for persons involved in the care of these children.

Therefore, the purpose of this study was to determine the differences in spatiotemporal gait parameters between children with spastic diplegic CP and ND children.

\section{SUBJECTS AND METHODS}

Sixteen children were recruited for participation as volunteers in this study. Eight children with spastic diplegic CP and eight ND children participated in this study. Children with CP had a Gross Motor Function Classification 
(GMFC) System level between I and II and removed their prescribed ankle-foot orthosis during the experiment. The ND children were not assessed with the GMFC. The following inclusion-exclusion criteria were used for selection of children with CP: (1) children with $\mathrm{CP}$ had to have a clinical diagnosis of spastic diplegic $\mathrm{CP}$; (2) children with $\mathrm{CP}$ had to be able to walk without use of assistive devices (i.e., walker, cane, and ankle-foot orthosis); and (3) children with $\mathrm{CP}$ had to have not undergone orthopedic surgery within at least one year and six months after botulinum toxin type A (Botox) injections prior to the experiment. All parents consented, and the children agreed to participation in the experiment; they provided written informed consent prior to their participation in the study in accordance with the ethical standards of the Declaration of Helsinki.

Objective gait analysis was performed using the OrthoTrak 6.4 system (Motion Analysis, Santa Rosa, CA, USA), and marker trajectories were obtained using an EVaRT 6.1 real-time tracking system (Motion Analysis, Santa Rosa, CA, USA) with an eight-camera system (Hawk system, Motion Analysis, Santa Rosa, CA, USA). Data from two force platforms embedded into a $10 \mathrm{~m}$ walkway were collected. For gait analysis, passive markers were attached with adhesive tape to the following locations of both lower limbs: the anterior superior iliac spine, sacrum, anterior aspect of the mid thigh, lateral femoral epicondyle of the knee and mid calf, lateral malleolus, base of the heel, and dorsum of the foot between the second and third metatarsals. The spatiotemporal parameters included walking velocity, cadence, stride length, and percentages of single- and double-limb support. Prior to data collection, all participants had an opportunity to practice walking. The participants walked at a comfortable gait speed in three trials.

The GMFM-66 (Gross Motor Functional Classification 66) is a standardized observational measurement designed for assessment of changes in five important gross motor function domains over time in children with CP. The five gross motor function domains, which include 66 testing items, include lying and rolling (four items); sitting (15 items); crawling and kneeling (10 items); standing (13 items); and walking, running, and jumping (24 items). The scoring system ranges from 0 ("does not initiate") to 3 ("complete") ${ }^{13)}$. High levels of validity, reliability, and responsiveness have been demonstrated in evaluations of motor function using the GMFC in children with $\mathrm{CP}^{14)}$.

Statistical analyses were performed using the SPSS version 17.0 software. An independent t-test was used for determination of differences in variables in terms of the baseline data (i.e., age, height, weight, and foot length) and spatiotemporal parameters (i.e., gait velocity, cadence, stride length, step width, stance phase, swing phase, and double-limb phase) between children with CP and ND children. The level of statistical significance was set at 0.05 .

\section{RESULTS}

The baseline demographic characteristics of the subjects enrolled in the study were as follows. Each group consisted of four male and four female subjects. The mean age, height,
Table 1. Comparison of spatiotemporal gait parameters in the $\mathrm{CP}$ and ND groups

\begin{tabular}{lcc}
\hline Parameters & $\begin{array}{c}\text { CP children } \\
(\mathrm{n}=8)\end{array}$ & $\begin{array}{c}\text { ND children } \\
(\mathrm{n}=8)\end{array}$ \\
\hline Walking velocity (m/min) & $63.99 \pm 11.22^{*}$ & $107.38 \pm 5.14$ \\
Cadence (step/min) & $89.39 \pm 8.04^{*}$ & $115.44 \pm 3.17$ \\
Stride length (cm) & $81.25 \pm 12.42^{*}$ & $111.31 \pm 3.20$ \\
Step width (cm) & $11.80 \pm 1.72^{*}$ & $7.38 \pm 0.72$ \\
Rt. SLS (\%/unit) & $33.68 \pm 2.41^{*}$ & $40.60 \pm 0.74$ \\
Lt. SLS (\%/unit) & $34.26 \pm 3.14^{*}$ & $41.73 \pm 0.61$ \\
Rt. IDLS (\%/unit) & $15.19 \pm 2.31^{*}$ & $8.80 \pm 0.56$ \\
Lt. IDLS (\%/unit) & $16.33 \pm 3.16^{*}$ & $9.11 \pm 0.58$ \\
Rt. TDLS (\%/unit) & $18.19 \pm 3.06^{*}$ & $8.88 \pm 0.67$ \\
Lt. TDLS (\%/unit) & $15.33 \pm 2.73^{*}$ & $8.59 \pm 0.55$ \\
\hline
\end{tabular}

* Significant difference between the CP and the ND children $(* \mathrm{p}<0.05)$.

$\mathrm{CP}$, children with cerebral palsy; ND, normal developmental child; SLS, single-limb support; IDLS, initial double-limb support; TDLS, terminal double-limb support

and weight of the children with $\mathrm{CP}$ were $8.2 \pm 0.75$ years, $125.6 \pm 7.05 \mathrm{~cm}$, and $30.5 \pm 3.35 \mathrm{~kg}$, respectively, and those of the ND children were $9.1 \pm 0.44$ years, $137.1 \pm 2.78 \mathrm{~cm}$, and $34.6 \pm 2.79 \mathrm{~kg}$, respectively. Four of the children with $\mathrm{CP}$ were classified as GMFC level I, four children were classified as GMFC level II. Data (mean \pm SD) for the spatiotemporal gait parameters of both the children with $\mathrm{CP}$ and the ND children are shown in Table 1. Significant differences in terms of spatiotemporal gait parameters were observed between the two groups. The scores for walking velocity, cadence, and stride length in the children with $\mathrm{CP}$ were lower compared with the ND children, whereas the score for step width was higher in the $\mathrm{CP}$ children compared with the ND children. The periods of right and left single-limb stance in the children with CP group were shorter compared with the ND children, whereas those for right and left double-limb stance were longer in children with $\mathrm{CP}$ compared with the ND children.

\section{DISCUSSION}

The aim of this study was to describe differences in spatiotemporal gait parameters between children with spastic diplegic CP, who had GMFC System levels of I or II, and ND children, and to determine the extent of the differences. Our findings showed significantly lower spatiotemporal gait parameters, including walking velocity, cadence, and stride length in children with spastic diplegic $\mathrm{CP}$ than in ND children. Step width was larger in children with CP due to poor balance and gait instability. In addition, significant differences in proportions of the stance phase (single- and double-limb stance) were observed in children with spastic diplegic CP compared to ND children. The duration of single-limb support in children with spastic diplegic CP was shorter, and that of double-limb support was longer.

Our findings are consistent with those of previous studies reporting deteriorated gait function and altered gait pat- 
tern in children with spastic diplegic $\mathrm{CP}^{8,15}$. The findings of the current study showed that walking velocity, cadence, stride length, and step width of children with $\mathrm{CP}$ with a GMFC of between I and II were a level of $60 \%, 77 \%, 73 \%$, and $160 \%$, respectively, of those of ND children. Because of motor weakness and poor voluntary motor control, children with CP use a wider step width than ND children ${ }^{16)}$, suggesting that children with $\mathrm{CP}$ may choose a wider base of support in order to stabilize the center of mass. In addition, step width showed correlation with walking velocity, cadence, and stride length. Thus, children with a wider step width tend to have greater difficulty in gait performance.

The percentages of right and left double-limb support and of right and left single-limb support during stance phase were $188 \%$ and $179 \%$ higher and $83 \%$ and $82 \%$ lower, respectively, compared with the ND children. This is because reduced hip adduction in the stance phase increases the internal abduction moment of the support limb. Previous studies have reported that children with spastic diplegic CP show weakness of the hip abductor muscles $\left.{ }^{17,} 18\right)$. Thus, the gait pattern would be unstable, and less time would be spent in single-limb support.

Children with spastic diplegic CP with a GMFC level of I are expected to walk independently indoors and outdoors and to go up and down stairs. Children with a GMFC level of II hold onto a rail when walking on stairs and are limited with respect to walking long distances. Thus, the differences between the school-age 7 to 12 years old children with spastic diplegic CP (GMFM levels I and II) and agematched ND children included limitations in walking outdoors and inside the school, walking on uneven surfaces, and walking in crowded places.

Our results provide objective evidence of distinct differences in spatiotemporal gait parameters between children with spastic diplegic CP with a GMFC level of I or II and ND children and would be helpful to persons involved in the care of these children. The therapeutic approach to management of children with $\mathrm{CP}$, who have a wide base of support and decreased capacity to shift weight, should be considered for improvement of ability to maintain singlelimb support and for improvement of ability to shift weight in order to reduce the period of double-limb support. Due to the small number of children with CP in the present study, some limitations could be raised and should be taken into account when interpreting the data. In addition, because our study was only conducted in school-age children with spastic diplegic CP with a GMFC System level of between I and II, the results may not be generalized to those with more severe forms of CP. However, our study has meaningful significance in that it suggests quantitative value for spatiotemporal gait parameters for school-age children with spastic diplegic CP compared with ND children. Therefore, conduct of future studies may be needed in order to clarify this issue.

\section{REFERENCES}

1) Bax M, Goldstein M, Rosenbaum $P$, et al. Executive Committee for the Definition of Cerebral Palsy: Proposed definition and classification of cerebral palsy, April 2005. Dev Med Child Neurol, 2005, 47: 571-576. [Medline] [CrossRef]

2) Oeffinger DJ, Tylkowski CM, Rayens MK, et al.: Gross Motor Function Classification System and outcome tools for assessing ambulatory cerebral palsy: a multicenter study. Dev Med Child Neurol, 2004, 46: 311-319. [Medline] [CrossRef]

3) Beckung E, Hagberg G, Uldall P, et al. Surveillance of Cerebral Palsy in Europe: Probability of walking in children with cerebral palsy in Europe. Pediatrics, 2008, 121: e187-e192. [Medline] [CrossRef]

4) Jahnsen R, Villien L, Aamodt G, et al.: Musculoskeletal pain in adults with cerebral palsy compared with the general population. J Rehabil Med, 2004, 36: $78-84$.

5) Tedroff K, Knutson LM, Soderberg GL: Synergistic muscle activation during maximum voluntary contractions in children with and without spastic cerebral palsy. Dev Med Child Neurol, 2006, 48: 789-796. [Medline] [CrossRef]

6) Damiano DL, Kelly LE, Vaughn CL: Effects of quadriceps femoris muscle strengthening on crouch gait in children with spastic diplegia. Phys Ther, 1995, 75: 658-667, discussion 668-671. [Medline]

7) Steele KM, Demers MS, Schwartz MH, et al.: Compressive tibiofemoral force during crouch gait. Gait Posture, 2012, 35: 556-560. [Medline] [CrossRef]

8) Johnson DC, Damiano DL, Abel MF: The evolution of gait in childhood and adolescent cerebral palsy. J Pediatr Orthop, 1997, 17: 392-396. [Medline] [CrossRef]

9) van den Berg-Emons HJ, Saris WH, de Barbanson DC, et al.: Daily physical activity of schoolchildren with spastic diplegia and of healthy control subjects. J Pediatr, 1995, 127: 578-584. [Medline] [CrossRef]

10) Bjornson KF, Belza B, Kartin D, et al.: Ambulatory physical activity performance in youth with cerebral palsy and youth who are developing typically. Phys Ther, 2007, 87: 248-257. [Medline] [CrossRef]

11) Gormley ME Jr: Treatment of neuromuscular and musculoskeletal problems in cerebral palsy. Pediatr Rehabil, 2001, 4: 5-16. [Medline]

12) Schenker R, Coster WJ, Parush S: Neuroimpairments, activity performance, and participation in children with cerebral palsy mainstreamed in elementary schools. Dev Med Child Neurol, 2005, 47: 808-814. [Medline] [CrossRef]

13) Rosenbaum PL, Walter SD, Hanna SE, et al.: Prognosis for gross motor function in cerebral palsy: creation of motor development curves. JAMA, 2002, 288: 1357-1363. [Medline] [CrossRef]

14) Bjornson $\mathrm{K}$, Graubert $\mathrm{C}$, McLaughlin J: Test-retest reliability of the gross motor function measure in children with cerebral palsy. Pediatr Phys Ther, 2000, 12: 200-202. [Medline] [CrossRef]

15) Abel MF, Damiano DL: Strategies for increasing walking speed in diplegic cerebral palsy. J Pediatr Orthop, 1996, 16: 753-758. [Medline] [CrossRef]

16) Kurz MJ, Arpin DJ, Corr B: Differences in the dynamic gait stability of children with cerebral palsy and typically developing children. Gait Posture, 2012, 36: 600-604. [Medline] [CrossRef]

17) Winter DA: Biomechanics and Motor Control of Human movement, 3rd ed. Waterloo: Canada, 2005.

18) Burnfield JPaLM: Gait and Posture, 2nd ed. New Jersey: SLACK, 2010. 